\title{
NECESSIDADE DE SERVIÇOS TÉCNICOS E TECNOLÓGICOS DAS EMPRESAS CALÇADISTAS NA REGIÃO DO PARANHANA/RS
}

\author{
Cláudio Roberto Hoffmeister ${ }^{1}$ \\ Diego de Castro Vieira²
}

\begin{abstract}
RESUMO
Este artigo apresenta os resultados de uma pesquisa de caráter exploratório que teve como objetivo identificar, junto às indústrias calçadistas da Região do Paranhana, suas principais demandas em Serviços Técnicos e Tecnológicos (STT). A pesquisa foi realizada em duas fases, onde na primeira foram aplicados questionários em empresas deste ramo de atuação com perguntas direcionadas à identificação de necessidades de contratação de Serviços do SENAI, bem como a responder quais as suas principais demandas e a indicação das causas da pouca ou nenhuma utilização desses serviços. Na segunda fase, baseado nos dados coletados, foram analisados os resultados e apontados os principais fatores que venham a contribuir no direcionamento das ações do SENAI nas novas instalações no município de Igrejinha/RS. Nesse sentido, foi identificado que a concentração de empresas desse setor está nos municípios de Três Coroas e Igrejinha e que aproximadamente $53 \%$ dos entrevistados afirmam ter necessidade de contratação desses serviços, principalmente de assessoria e consultoria em processo produtivo. Também foi possível identificar que a principal causa da pouca ou nenhuma utilização dos serviços está relacionada à deficiência na divulgação, a distância da unidade do SENAI em relação aos estabelecimentos e à inexistência de atendimento específico para o setor.
\end{abstract}

Palavras-chave: Serviços Técnicos e Tecnológicos. Indústrias calçadistas. Pesquisa mercadológica.

\footnotetext{
${ }^{1}$ Especialista, e-mail: claudio.hoffmeister@senairs.org.br
}

${ }^{2}$ Especialista, e-mail: diegovieira@sc.senai.br 


\section{INTRODUÇÃO}

De acordo com o Serviço Nacional de Aprendizagem industrial (2002), após o início da década de 90, com a crescente exposição do País à competição internacional, novos aspectos estruturais da economia e da organização do setor produtivo demandaram uma expressiva mudança no ambiente das empresas industriais. A preocupação central das empresas passou a ser a permanente busca da inovação e a nova palavra de ordem, em todos os setores, passou a ser o conhecimento, visto ser ele o gerador de novas tecnologias.

Conforme Corrêa (2001), ao longo da década, mudaram as condições de produção e a concorrência na cadeia produtiva de calçados e, com isso, as empresas calçadistas do Sul e do Sudeste foram se deslocando para outras regiões à procura de mão-de-obra mais barata, de incentivos dos governos estaduais e, em alguns casos, buscando aproximar a produção do mercado externo. A pressão da concorrência obrigou o setor calçadista brasileiro, além de outras providências, a reduzir custos de produção e transporte. Como consequência, nesse período, muitas fábricas de calçados deixaram o Pólo Calçadista da Região do Paranhana e do Vale dos Sinos e se instalaram na região Nordeste.

Apesar do cenário competitivo, o setor calçadista brasileiro, segundo a ABICALÇADOS (2012), no ano de 2010 contempla mais de 8,2 mil indústrias, que produzem aproximadamente 893 milhões de pares/ano, tendo gerado cerca de 348 mil empregos diretos na indústria. De acordo com a associação, o Rio Grande do Sul é um dos maiores produtores de calçados do país e o Vale dos Sinos, que abriga cerca de mil e setecentas fábricas, é responsável por cerca de $40 \%$ da produção nacional. Já na Região do Paranhana, são produzidos cerca de 60 milhões de pares/ano, o equivalente a quase $10 \%$ do que é desenvolvido em território nacional.

Para o Serviço Nacional de Aprendizagem Industrial (2009), a tecnologia se justifica como parâmetro portador de competitividade para a indústria. Assim, a sua atuação por meio dos serviços técnicos e tecnológicos está diretamente relacionada com a promoção do suporte necessário para que as empresas possam dispor de melhores condições de competitividade. Seguindo essa filosofia, o Serviço Nacional de Aprendizagem Industrial (SENAI) está presente na Região do Paranhana, no município de Igrejinha, por meio da Agência de Educação Profissional SENAI Nelson Heidrich.

Com vistas a auxiliar no desenvolvimento dessa importante região produtora de calçados e conforme definição do Conselho Consultivo dessa Unidade Operacional está sendo projetada para o final do ano de 2013 a inauguração de uma nova sede neste município, com estrutura ampliada e com oferta de novos produtos e serviços. Nesse sentido, em recente pesquisa desenvolvida em 2011, foram definidas as principais áreas a serem atendidas na modalidade de Educação Profissional (EP) e identificado que boa parte das empresas pesquisadas desconhecem os Serviços Técnicos e Tecnológicos (STT) do SENAI, porém cerca de $42 \%$ das empresas entrevistadas demandam estes Serviços. 
Como forma de apresentar informações mais precisas, faz-se necessário uma pesquisa mais pontual, com ênfase na identificação dos STT mais demandados pelas empresas locais e que venha a subsidiar o SENAI no direcionamento de suas ações de forma alinhada às necessidades atuais do setor calçadista, bem como a busca no atendimento das novas diretrizes nacionais de aumento na atuação desta modalidade.

O principal objetivo deste estudo foi identificar junto às indústrias calçadistas da Região do Paranhana suas principais demandas em Serviços Técnicos e Tecnológicos. Para isso, elencaram-se os seguintes objetivos específicos:

a) elaborar revisão de literatura sobre serviços;

b) levantar as principais demandas de STT;

c) delimitar e identificar empresas a serem entrevistadas; e

d) apresentar os resultados obtidos com a aplicação da pesquisa e suas contribuições para o SENAI.

\section{A IMPORTÂNCIA DOS SERVIÇOS}

Com a agilidade das transformações globais, principalmente no âmbito econômico, as atividades de serviços têm sido consideradas de grande importância para o desenvolvimento mundial (GIANESI; CORRÊA, 1996).

Segundo os autores, a importância das atividades de serviços em nossa sociedade pode ser demonstrada, por um lado, pela posição que ocupam na economia, seja por meio da participação no Produto Interno Bruto (PIB), seja na geração de empregos e pela análise das tendências e transformações que a economia mundial está experimentando.

Confirmando esse pensamento, Corrêa e Caon (2002, p. 23) afirmam que:

O setor de serviços, além de ser responsável pela maior parcela do PIB mundial, apresenta-se, talvez, como a parcela mais dinâmica da economia, pois sua participação no PIB e o número de empregos no setor crescem a taxas mais elevadas do que nos demais setores econômicos.

Para o setor industrial, as atividades de serviços também representam um importante papel na economia. Para Gianesi e Corrêa (1996), esse papel pode ser resumido em três categorias:

- como diferencial competitivo;

- como suporte às atividades de manufatura;

- como geradores de lucro. 
Para os autores, no Brasil, as estatísticas não se mostram diferentes da tendência apresentada no mundo industrializado. Em termos de ocupação de mão-de-obra, o setor de serviços vem aumentando sua participação nas últimas décadas, como mostra o gráfico 01. Nesse gráfico, está representada a participação percentual dos três principais setores da economia, segundo a classificação do Instituto Brasileiro de Geografia e Estatística (IBGE).

Gráfico 1: Ocupação de mão-de-obra nos setores da economia

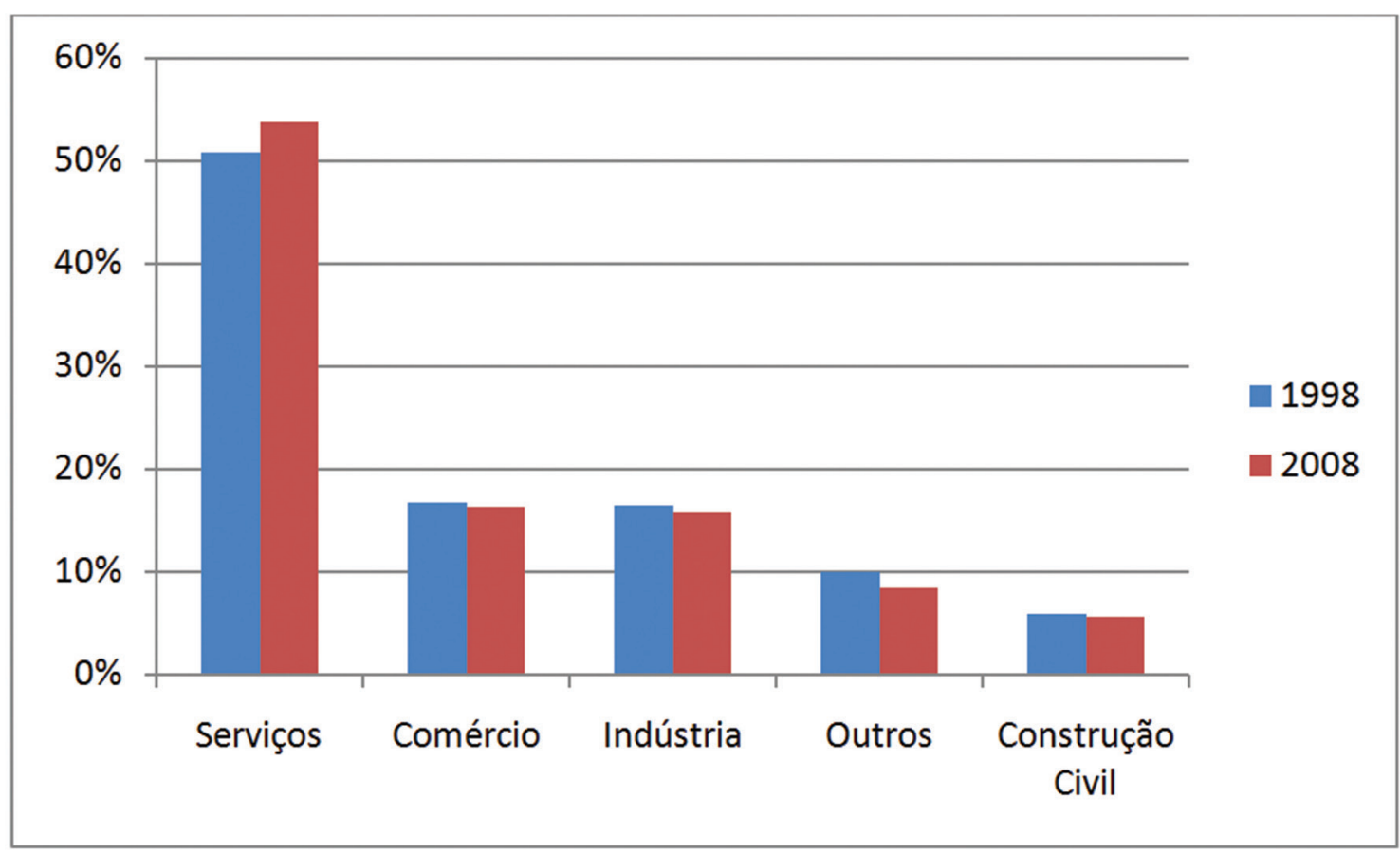

Fonte: Brasil (2009, p. 02)

O gráfico 01 apresenta a evolução da ocupação de mão-de-obra no setor de serviços e a consequente queda nos demais setores da economia brasileira, tais como: comércio, indústria, entre outros.

A partir da análise do gráfico, percebe-se a importância de desenvolver conceitos e técnicas de administração para as operações de serviços, pelo menos com a mesma ênfase que tem sido dada à manufatura, para que não se corra o risco de ter a economia dominada por uma atividade pouco produtiva e vulnerável à competição internacional. 


\subsection{0 projeto do serviço}

O desenvolvimento de produtos e serviços tem se tornado processos-chave para a competitividade. Movimentos de aumento da concorrência, rápidas mudanças tecnológicas, diminuição do ciclo de vida dos produtos e serviços e maior exigência por parte dos consumidores, exigem das empresas agilidade, produtividade e alta qualidade, que dependem necessariamente da eficiência e eficácia da empresa nesse processo.

Para Davis (2001), nos serviços, os clientes tipicamente interagem de forma direta com o processo de entrega do serviço, já a produção e o consumo ocorrem ao mesmo tempo. Os serviços são considerados intangíveis e não podem ser estocados. Para o autor, essa é a principal e relevante diferença entre as operações de manufatura e os processos de serviços.

Segundo Moreira (2001), o projeto de um novo bem ou serviço começa com a geração de uma ideia, que envolve a necessidade de um cliente e uma forma de resolvê-la, e vai em frente por meio de várias fases de teste e desenvolvimento. Finalmente, chega-se ao ponto de ter especificações detalhadas para a produção, que começa a introduzir o produto no mercado. Aparentemente, o projeto de um produto ou serviço é uma tarefa única para novos itens e depois nenhuma alteração é necessária. Em geral, porém, o ambiente em que as empresas operam é dinâmico e existem pressões constantes para mudanças de projeto, vindas do mercado, da legislação ou de dentro da própria empresa. Dessa maneira, o projeto original está frequentemente sujeito a constantes alterações ao longo do tempo.

Segundo os autores citados acima, o grande diferencial está na interação direta dos clientes com o processo de entrega do serviço, porém, em sua concepção, tem grande similaridade com o desenvolvimento de produtos.

\subsection{Serviços Técnicos e Tecnológicos no SENAI}

Para o Serviço Nacional de Aprendizagem Industrial (2009), os Serviços Técnicos e Tecnológicos são ações destinadas à criação, inovação e/ou melhoria de processos e produtos ou ao desenvolvimento de conhecimentos e informações sobre os mesmos, bem como à certificação de produtos e processos.

A seguir, estão descritas as Linhas de Serviços Técnicos e Tecnológicos do SENAl e suas respectivas Categorias. 
Quadro 1: Classificação das Ações do SENAI

Pesquisa, Desenvolvimento e Inovação Tecnológica

- Pesquisa Aplicada

- Desenvolvimento e Inovação de Produtos e Processos Serviços Técnicos Especializados

- Serviços Laboratoriais

- Serviços de Inspeção

- Serviços Operacionais

Assessoria Técnica e Tecnológica

- Assessoria e Consultoria em Gestão Empresarial

- Assessoria e Consultoria em Processo Produtivo

- Assessoria e Consultoria em Segurança no Trabalho

- Assessoria e Consultoria em Meio Ambiente Informação Tecnológica

- Elaboração e Disseminação de Informações

- Estudos de Mercado

- Eventos Técnicos

Certificação de Processos e de Produtos

- Certificação de Processos

- Certificação de Produtos

Fonte: Serviço Nacional de Aprendizagem Industrial (2009, p. 28)

\section{ESTUDO APLICADO}

\subsection{Cenário}

Nos dias atuais, a preocupação em atender e satisfazer a necessidade do consumidor faz com que os profissionais devem conhecer o mercado alvo e isso significa que é de responsabilidade destes profissionais o desenvolvimento dos produtos, vendas, publicidade, propaganda, comportamento do consumidor, pesquisa mercadológica, entre outras atividades (MORAIS, 2007). Também, de acordo com o autor, para conhecer o cliente é necessário identificá-lo e descrevê-lo, e isso é denominado segmentação de mercado e representa conhecer as preferências dos consumidores, saber a localização, suas atitudes, hábitos e frequência de compras.

Então, com todos esses parâmetros citados, o presente artigo buscou conhecer o cenário da pesquisa que se realizou na Região do Paranhana, nas cidades de Parobé, Taquara, Igrejinha Três Coroas, Rolante e Riozinho. 
Sujeitos da pesquisa são pessoas que fornecerão os dados de que se necessita (VERGARA, 2004). Assim, para esta pesquisa, foram selecionados profissionais especialistas em empresas fabricantes de calçados, atuantes e conhecedores da região de abrangência do estudo, o que possibilitou um diagnóstico, segundo sua visão, acerca do setor calçadista, o que gerou um melhor entendimento do objetivo do trabalho.

Os critérios para a seleção dos entrevistados atenderam aos seguintes aspectos: empresas da Região do Paranhana, indicadas pelos Sindicatos das Indústrias de Igrejinha, Três Coroas e Parobé, que abrangem toda a região citada. Dentre os critérios adotados para esta escolha estavam: as empresas deviam possuir mais de 100 funcionários, mais de 10 anos de existência, ter produtos de marca própria, ser exportadoras, e, além disso, deviam ser reconhecidas no meio empresarial por um posicionamento (vanguarda) diferenciado no mercado.

Para quantificar e selecionar as indústrias a serem entrevistadas, foram repassadas as características aos Sindicatos, que indicaram os nomes a serem contatados.

\subsection{Procedimentos metodológicos}

Os resultados apresentados neste artigo foram obtidos a partir de uma pesquisa de caráter exploratório quanto aos objetivos e procedimentos, porque neles obteve-se a compreensão dos fenômenos individuais, organizacionais e sociais (YIN, 2001).

Conforme definição de Jung (2004), a pesquisa exploratória tem por característica a coleta de dados que servirão de base para formulação de modelos explicativos e inovadores.

A pesquisa foi efetuada em duas fases, sendo a primeira delas a aplicação de um questionário com oito questões fechadas, em 87 empresas, de acordo com os critérios de seleção. A partir dessa coleta de dados foram extraídas as respostas, dividindo-as em categorias e subcategorias de cada respondente e tabulado em uma planilha eletrônica. Do universo selecionado, $84 \%$ destes responderam ao questionário, totalizando 73 respondentes.

\subsection{Instrumento para coleta de dados}

O instrumento de coleta partiu dos quatros objetivos propostos por Hague e Jackson (1997) para elaboração do questionário, que são: (i) coletar as informações exatas dos entrevistados, (ii) a amostra não pode ser pequena e a pergunta deve ser feita da mesma forma a todos os entrevistados, (iii) um formulário padronizado deve ser elaborado para registrar os fatos e os dados, (iv) as respostas dos entrevistados devem ser registradas no mesmo lugar em cada questionário para facilitar a contagem e análise dos dados. A partir da proposta, elaborou-se um questionário para aplicação, conforme Apêndice Instrumento de Pesquisa. 


\subsection{Resultados obtidos}

Por meio de representação gráfica pode-se estabelecer uma associação entre termos numéricos e uma figura geométrica (SAMARA; BARROS, 2007). Para os autores, uma pesquisa mercadológica, quando representada graficamente, facilita a visualização de dados numéricos, sendo que os mais usados são os gráficos em barras, setores e curvas. A partir da descrição estão representadas as questões aplicadas no campo da pesquisa, associadas aos respectivos gráficos de barras para a apresentação dos dados.

Percebe-se que os resultados do gráfico 2 mostram os percentuais das empresas pesquisadas e a respectiva distribuição do número de estabelecimentos nos municípios que compõem a Região do Paranhana, relativos à Questão 1 do questionário aplicado. Destaca-se a concentração das empresas no município de Três Coroas (30\%), Igrejinha (22\%), seguidos de Rolante e Parobé (18\%). Demais municípios, listados a seguir.

Gráfico 2: Participação (\%) de estabelecimentos pesquisados por município da Região do Paranhana.,

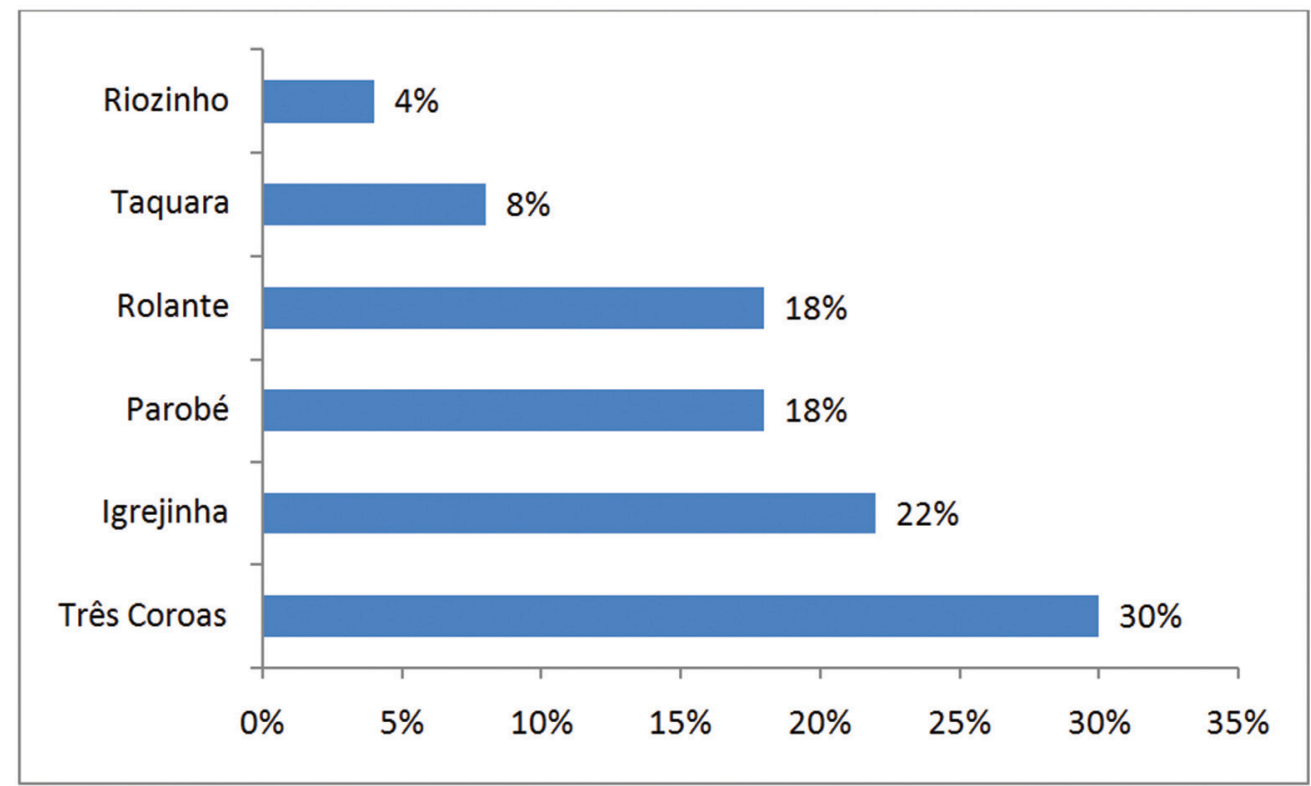

Fonte: Dos autores (2012)

Quase a metade das entrevistas realizadas nas empresas ocorreu com os "sócios ou proprietários" (48\%), seguido pelos "gerentes", com 20\%. Em 18\% das empresas pesquisadas, foram os "Supervisores/Técnicos" que responderam a pesquisa, $8 \%$ os "diretores" e no campo "outros", apenas 6\% (gráfico 3). 
Gráfico 3: Participação (\%) do cargo do entrevistado

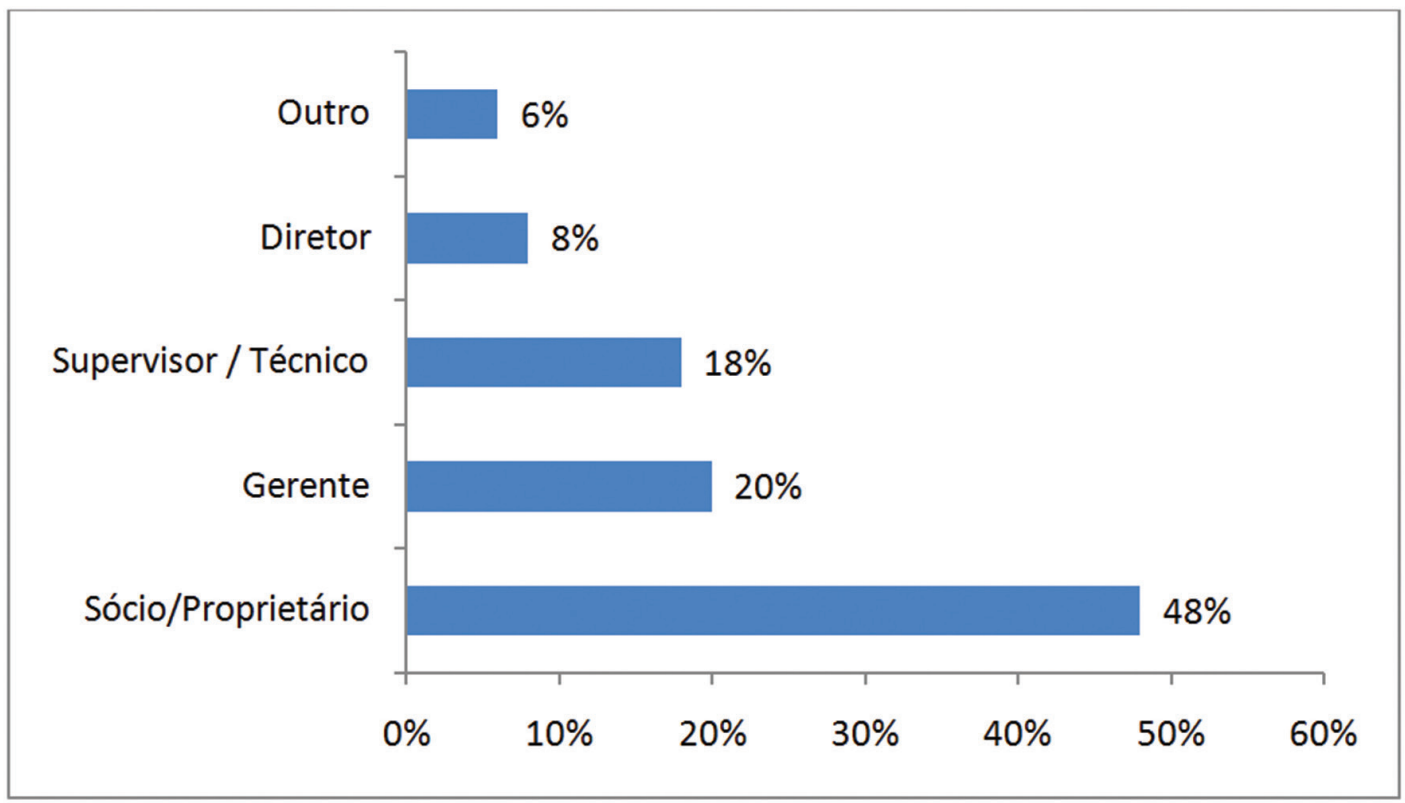

Fonte: Dos autores (2012)

Em relação aos Serviços Técnicos e Tecnológicos (STT) oferecidos pelo SENAI, observouse que $65 \%$ dos estabelecimentos industriais pesquisados afirmam conhecer os serviços do SENAI. Já $24 \%$ apontam que não possuem conhecimentos sobre os STT. Dentre os respondentes, $11 \%$ indicam não saber opinar sobre o assunto (gráfico 4).

Gráfico 4: Percentual (\%) do conhecimento, por parte dos estabelecimentos industriais pesquisados, sobre os Serviços Técnicos e Tecnológicos do SENAI

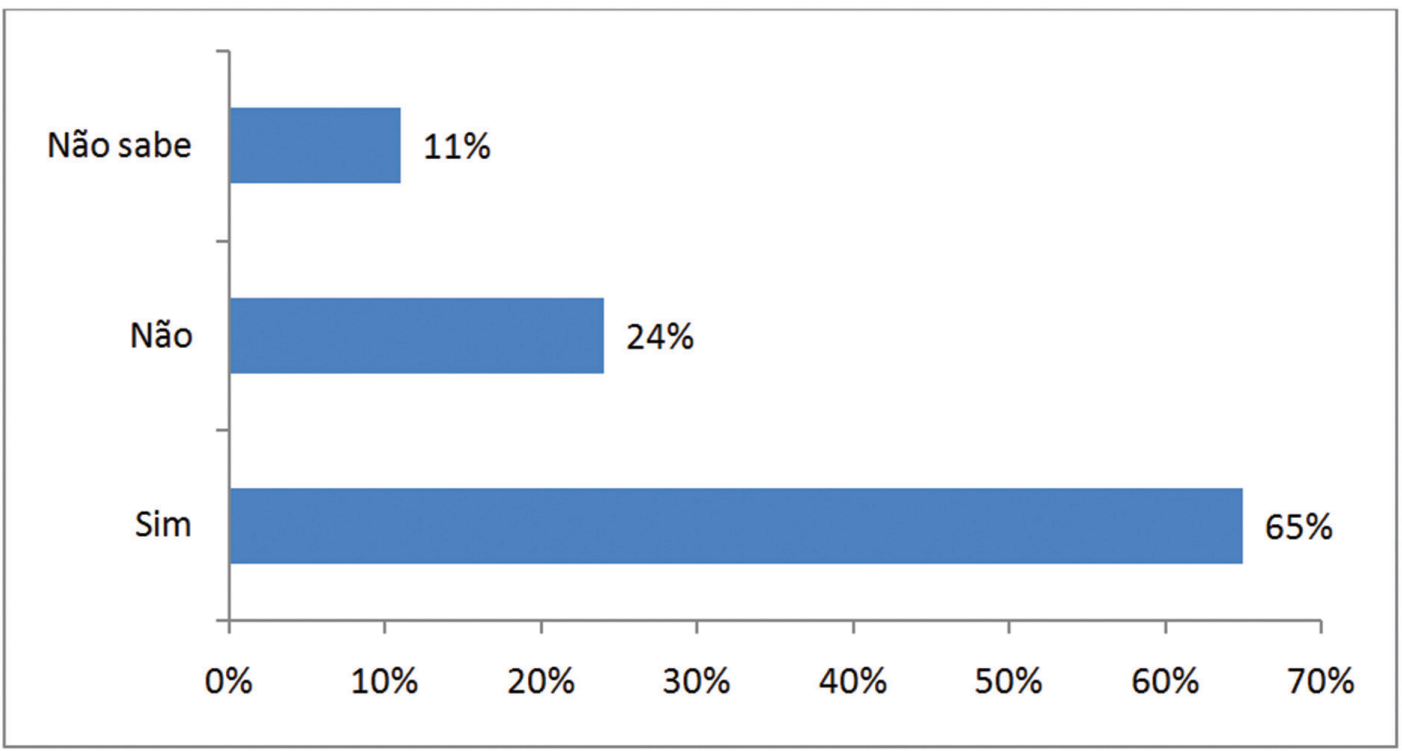

Fonte: Dos autores (2012) 
Em relação à necessidade de contratação de STT que o SENAI dispõe 53\% das empresas consultadas afirmam ter essa necessidade, já $22 \%$ das empresas indicam que não possuem necessidade de STT. Do total das empresas pesquisadas, $25 \%$ não sabem identificar se existe ou não a necessidade de contratação (gráfico 5).

Gráfico 5: Percentual (\%) da necessidade de contratação de STT, por parte dos estabelecimentos industriais pesquisados

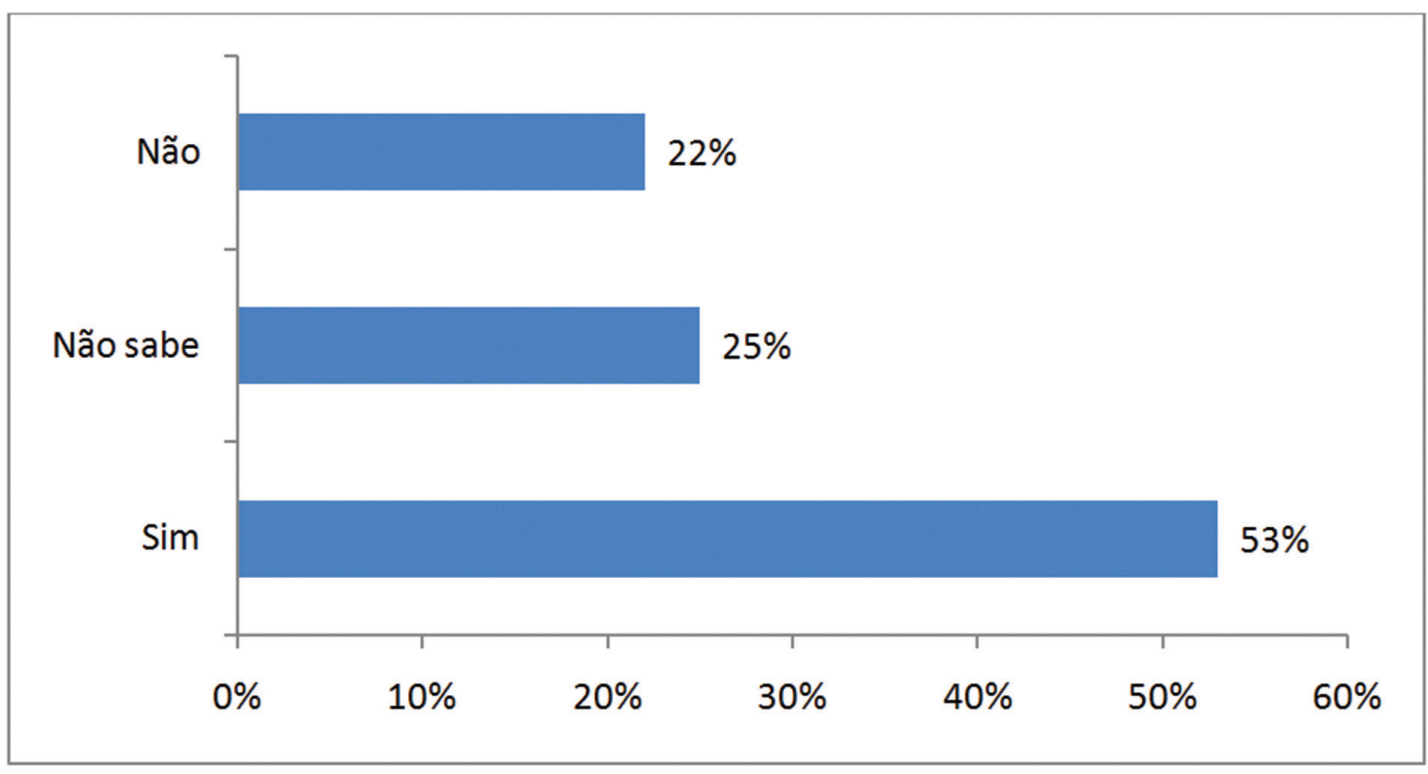

Fonte: Dos autores (2012)

Para aqueles estabelecimentos industriais pesquisados que identificam a necessidade de contratação de STT, foi solicitado que indicassem, dentre os serviços técnicos e tecnológicos oferecidos pelo SENAI, aquele(s) de interesse ao seu estabelecimento. Neste sentido a "Assessoria e consultoria em processo produtivo" obteve o maior número de citações (22\%). Na sequencia, "Serviços operacionais" com 19\%, "Assessoria e consultoria em gestão empresarial" com 11\%, "Assessoria e consultoria em saúde e segurança no trabalho" com 10\%, "Design" aparece com $8 \%$ das citações. Demais STT citados, listados a seguir (gráfico 6). 
Gráfico 6: Percentual (\%) da demanda por Serviços Técnicos e Tecnológicos oferecidos pelo SENAI

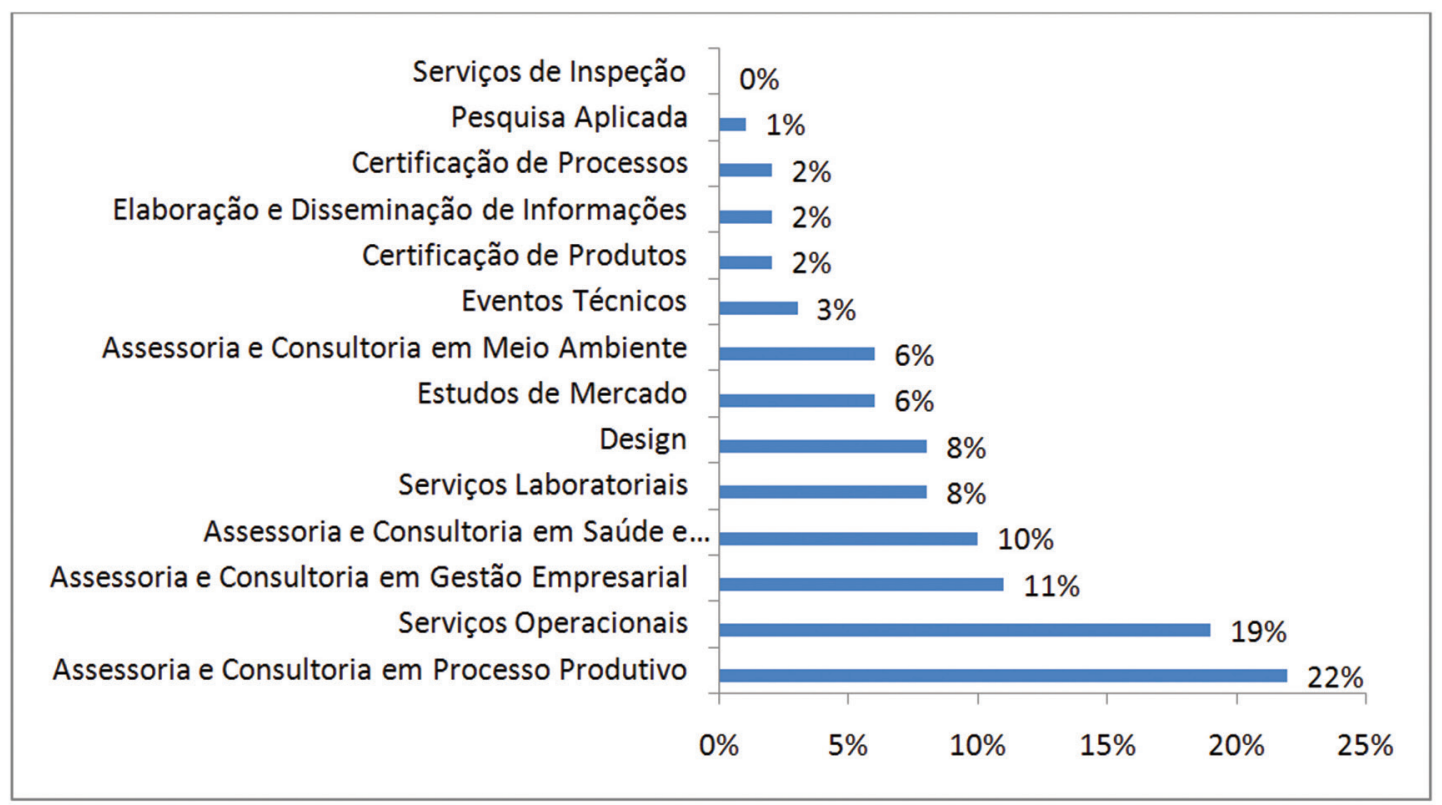

Fonte: Dos autores (2012)

Em relação ao nível de conhecimento que as empresas pesquisadas possuem do SENAI, verifica-se que a maioria das empresas indicam conhecer o SENAI "um pouco" (74\%), já 19\% afirmam conhecer bem o SENAI e apenas 7\% dos respondentes disseram "não conhecer" o SENAI (gráfico 7).

Gráfico 7: Percentual (\%) do nível de conhecimento dos estabelecimentos pesquisados, em relação ao SENAI

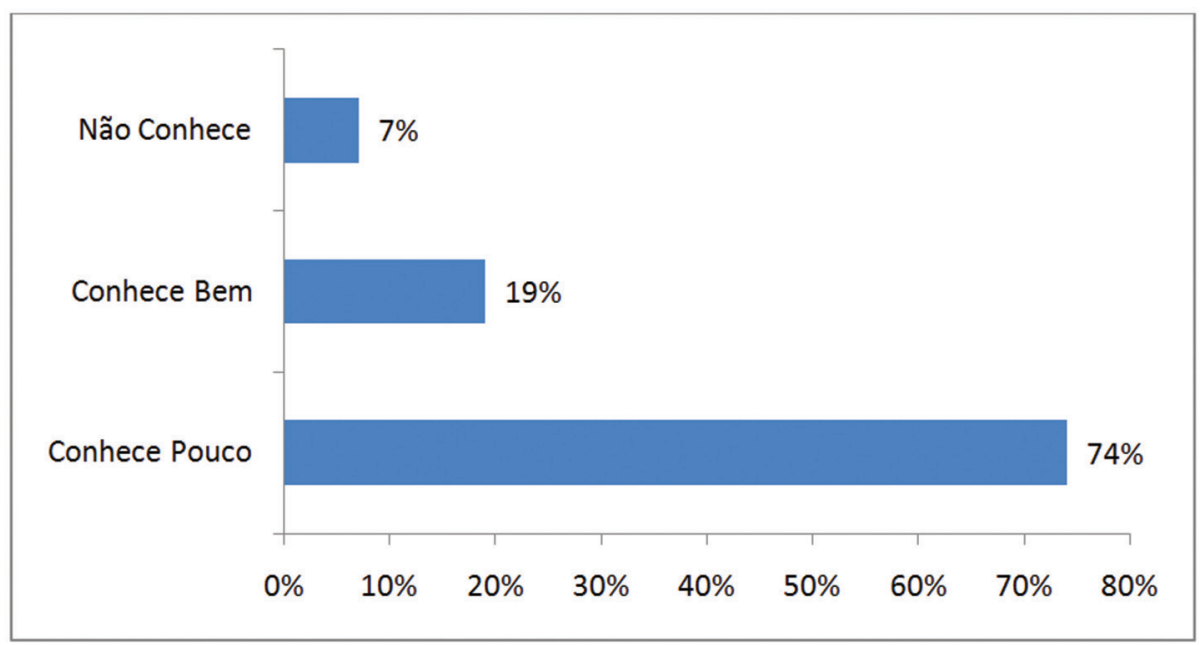

Fonte: Dos autores (2012) 
Somando ao questionamento do nível de conhecimento dos produtos e serviços do SENAI, buscou-se também identificar o grau de utilização destes serviços, assim constata-se que mais da metade das empresas pesquisadas já utilizou os serviços do SENAI, dentre estas, 55\% utilizaram pouco e 6\% utilizou muito. Existe, porém, 39\% das empresas que participaram da pesquisa que afirmam nunca terem utilizado os serviços do SENAI (gráfico 8).

Gráfico 8: Percentual (\%) sobre a utilização de serviços do SENAI

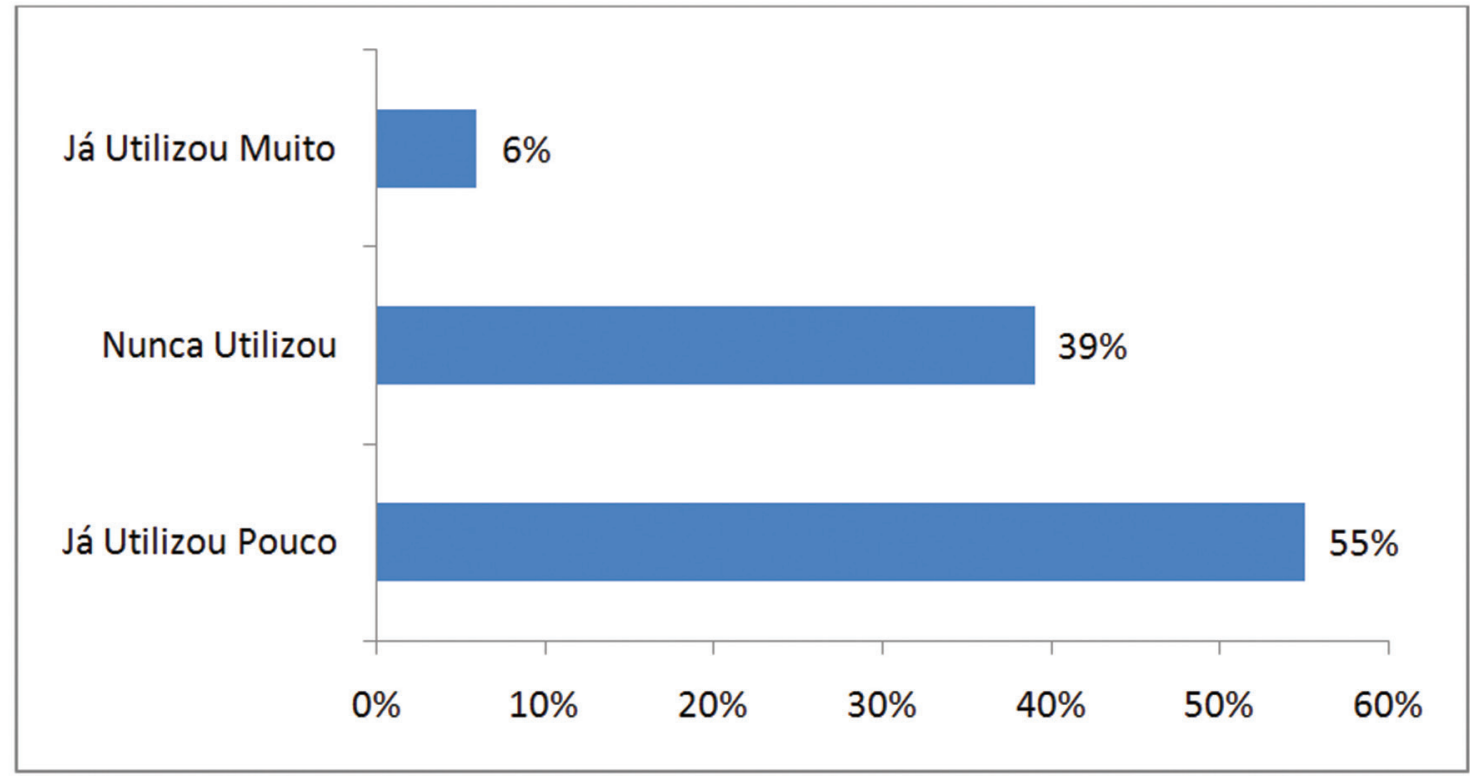

Fonte: Dos autores (2012)

Para o conjunto das empresas que nunca utilizaram ou que utilizaram pouco os serviços do SENAl, pode-se identificar as razões que justificam essa situação. Para elas, a principal razão apontada é a deficiência na divulgação, por parte do SENAI (25\%), outro fato que impacta nesta questão, é à distância da unidade do SENAI, em relação aos estabelecimentos (20\%), a inexistência de atendimento específico para o setor, é a razão apontada para $17 \%$ das empresas que nunca utilizaram ou utilizaram pouco os serviços do SENAI. Demais razões listadas a seguir (gráfico 9). 
Gráfico 9: Participação (\%) das razões de não ter utilizado, ou ter utilizado pouco os serviços prestados pelo SENAI

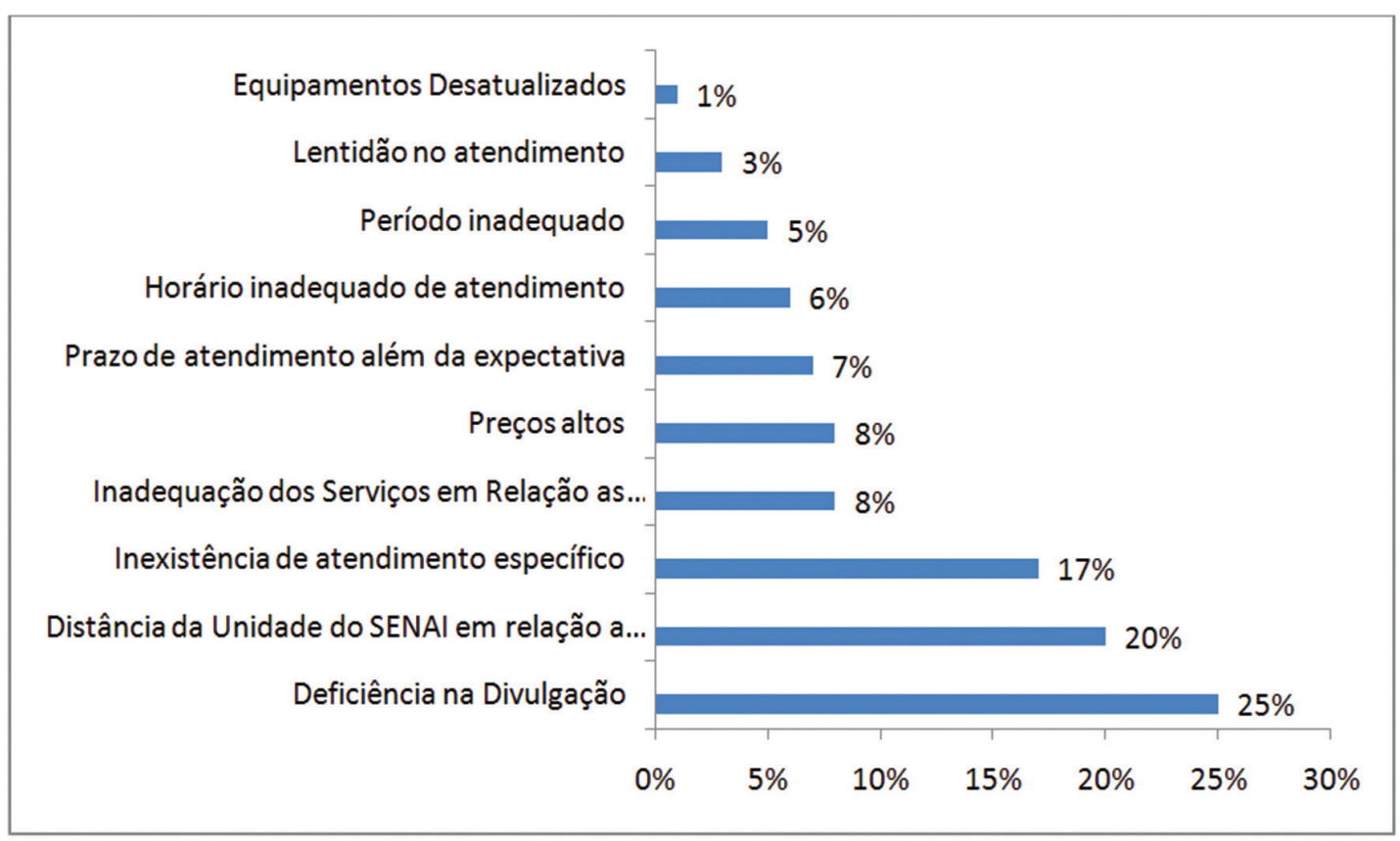

Fonte: Dos autores (2012)

Considerando os resultados apresentados acima, pode-se destacar que 53\% dos estabelecimentos pesquisados afirmaram ter necessidade de contratação de Serviços Técnicos e Tecnológicos (Gráfico 05) e destes, quando questionados sobre suas principais necessidades de contratação nas modalidades oferecidas pelo SENAI (Gráfico 06), $22 \%$ indicaram a Assessoria e Consultoria em Processo Produtivo e $19 \%$ os Serviços Operacionais como suas prioridades. No sentido de direcionar e ampliar as ações referentes a estes aspectos, a deficiência na divulgação foi a razão apontada por $25 \%$ (Gráfico 09) para a não utilização dos Serviços.

\section{CONCLUSÃO}

Este artigo apresentou os resultados obtidos por meio da aplicação de uma pesquisa exploratória realizada com as empresas calçadistas da Região do Paranhana, que compõem a área de jurisdição do SENAI Nelson Heidrich - Igrejinha/RS, referente às suas principais demandas em Serviços Técnicos e Tecnológicos. Para o melhor entendimento e desenvolvimento dos trabalhos, fez-se necessário buscar auxílio de alguns autores para definir o que são Serviços e quais as linhas de trabalho disponíveis no SENAI. Também, a definição e delimitação das empresas a serem entrevistadas, que contou com o apoio dos Sindicados das Indústrias desta região, possibilitou o direcionamento da pesquisa ao público alvo, obtendo 73 respondentes. A partir da elaboração e aplicação do questionário 
com perguntas direcionadas e objetivando colher informações dos entrevistados, podese processar a tabulação e avaliação dos resultados.

Por meio da primeira questão do questionário foi possível identificar nos municípios pesquisados, qual a concentração de empresas e facilitar o direcionamento de esforços. Já a segunda questão mostrou qual o cargo ocupado pelo entrevistado na empresa, sendo que a grande maioria foram proprietários/sócios, diretores e gerentes. Na terceira, o objetivo foi medir o percentual de empresas que conhecem os serviços do SENAI, onde foi apontado que $65 \%$ delas já os conhecem.

A quarta questão tratou da necessidade de contratação dos Serviços Técnicos e Tecnológicos do SENAI e o resultado apontou que 53\% das empresas consultadas afirmam ter essa necessidade. Para auxiliar no direcionamento das futuras ações a quinta questão identificou, junto às empresas que informaram ter esta necessidade, que as principais demandas estão concentradas nas atividades "Assessoria e consultoria em processo produtivo", "Serviços operacionais", "Assessoria e consultoria em gestão empresarial", "Assessoria e consultoria em saúde e segurança no trabalho" e "Design".

O seguinte questionamento apontou que $74 \%$ dos respondentes indicam conhecer o SENAI "um pouco" e a sétima pergunta trouxe o resultado de que mais da metade dos entrevistados já utilizou os serviços do SENAI, porém a grande maioria utilizou pouco (55\%) e ainda que $39 \%$ nunca utilizaram. Para estes, foi perguntado quais as razões para a pouca ou nenhuma utilização dos serviços e as principais apontadas foram a deficiência na divulgação, a distância da unidade do SENAI em relação aos estabelecimentos e a inexistência de atendimento específico para o setor.

De posse dessas informações entende-se que os objetivos foram plenamente atendidos e que os resultados apresentados trazem importantes subsídios para o correto direcionamento das ações do SENAI nas novas instalações nesta importante região produtora calçadista.

Como sugestão, no sentido de contribuir com o desenvolvimento de um projeto de sustentabilidade em STT e no atendimento das diretrizes nacionais do SENAI no aumento desta modalidade, entende-se como fundamental a seleção e contratação de técnicos que contemplem e completem o quadro de pessoal conforme as áreas mais demandadas na pesquisa, além da capacitação de colaboradores no atendimento e desenvolvimento desses serviços. Também, a sensibilização de empresas e consequente desenvolvimento de atividades em STT que sirvam de benchmarking, podem colaborar neste propósito. 


\title{
THE NEED OF TECHNICAL AND TECHNOLOGICAL SERVICES FOR FOOTWEAR COMPANIES OF THE PARANHANA / RS REGION
}

\begin{abstract}
This article presents the results of an exploratory study that aimed at identifying together with shoe industries of the Paranhana region their main demands in Technical Services and Technology (STT). The research was conducted in two phases, whereas in the first phase questionnaires were applied in firms of this branch of activity with questions aimed at identifying the needs for hiring services from Senai, as well as on their main demands and indication of the causes of little or no use of these services. In the second phase, based on the data collected, the results were analyzed and pointed out the key factors that will contribute to guide the actions of Senai in new facilities in the municipality of Igrejinha / RS. In this sense, it was identified that the concentration of companies in this sector is in the municipalities of Três Coroas and Igrejinha and that approximately $53 \%$ of respondents say they need to hire these services, mainly advisory and consulting in the production process. Also, it was possible to point out that the main cause of little or no use of services is related to a deficiency in the advertising, the distance of the unit of Senai from the establishments and the lack of specific assistance to this particular sector.
\end{abstract}

Keywords : Technical and Technological Services . Footwear industries . Market research

\section{REFERÊNCIAS}

ABICALÇADOS. Resenha Estatística 2012. Novo Hamburgo: Abicalçados, 2012.

Disponível em: <http://abicalcados.com.br/estatisticas>. Acesso em: 06 out. 2012.

BRASIL. Ministério do trabalho e emprego. Boletim de Trabalho na Construção 2009. Brasília, 2009.Disponível em: <http://portal.mte.gov.br>. Acesso em: 08 out. 2013.

CORRÊA, Abidack Raposo. Complexo Coureiro-Calçadista Brasileiro. Rio de Janeiro, 2001. Disponível em: <http://www.bndes.org.br/Setorial Calçado>. Acesso em: 06 out. 2012. 
CORRÊA, Henrique Luiz; CAON, Mauro. Gestão de Serviços: lucratividade por meio de operações e satisfação dos clientes. 1. ed. São Paulo: Atlas, 2002.

DAVIS, Mark M.; AQUILANO, Nicholas J.; CHASE, Richard B. Fundamentos da Administração da Produção. 3. ed. Porto Alegre: Bookman Editora, 2001.

GIANESI, Irineu G. N., CORRÊA, Henrique Luiz. Administração estratégica de serviços: operações para a satisfação do cliente. 1. ed. São Paulo: Atlas, 1996.

HAGUE, Paul; JACKSON, Peter. Faça sua própria pesquisa de mercado. São Paulo: Nobel, 1997.

JUNG, Carlos Fernando. Metodologia para pesquisa \& desenvolvimento: aplicada a novas tecnologias, produtos e processos. Rio de Janeiro: Axcel Books, 2004.

MORAIS, Roberto Tadeu Ramos. Administração: conceitos e práticas. Taquara: FACCAT, 2007.

MOREIRA, Daniel Augusto. Administração da produção e operações. 1. ed. São Paulo: Pioneira, 2001.

SAMARA, Beatriz Santos; BARROS, José Carlos de. Pesquisa de Marketing: conceitos e metodologia. 4. ed. São Paulo: Pearson Prentice Hall, 2007.

SERVIÇO NACIONAL DE APRENDIZAGEM INDUSTRIAL. Departamento Nacional. Classificação das ações do SENAI / SENAI.DN. 2. ed. Brasília, 2009.

. Departamento Regional do Rio Grande do Sul. Identificação das necessidades de formação e aperfeiçoamento de recursos humanos e assessoria técnica e tecnológica - Indústrias da área de jurisdição do Centro de Educação Profissional SENAI Waldemar Strassburger: relatório de pesquisa. Porto alegre, 2002.

VERGARA, Sylvia Constant. Projetos e relatórios de pesquisa em administração. 5. ed. São Paulo: Atlas, 2004.

YIN, Robert K. Estudo de Caso: planejamento e métodos. 2 ed. São Paulo: Bookman, 2001. 


\section{SOBRE OS AUTORES}

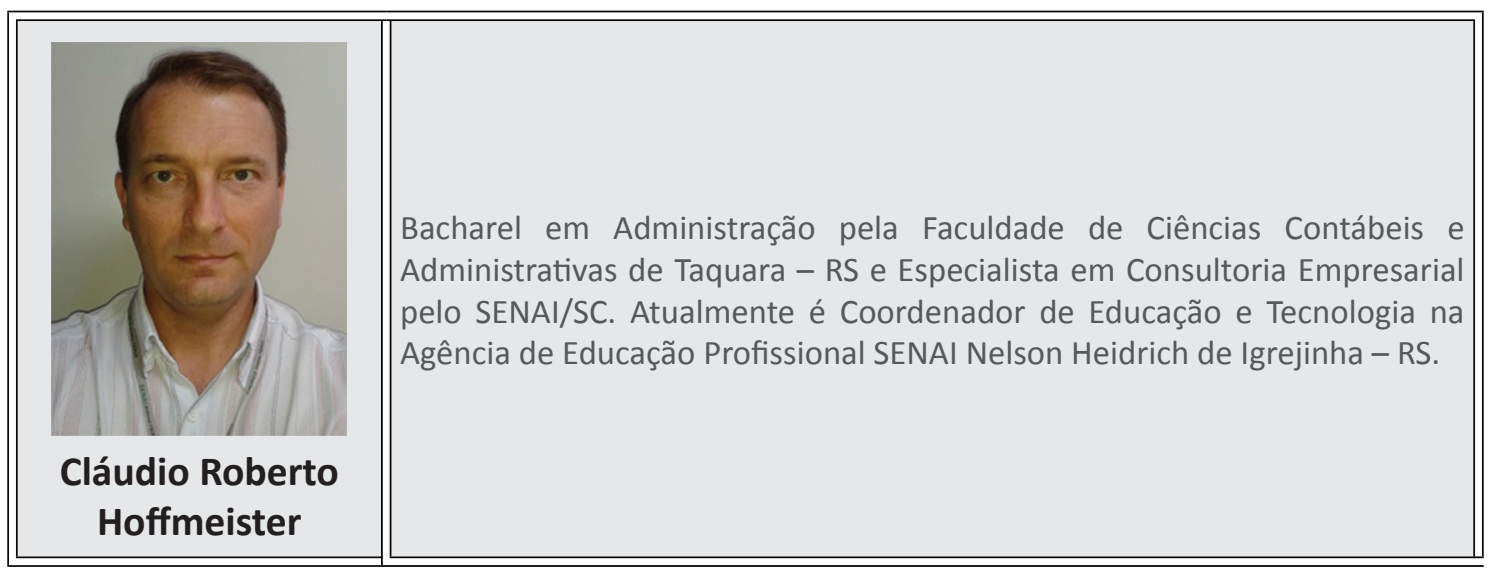

\begin{tabular}{|c|l||}
\hline Mestrando Profissional em Gestão de Unidades de Informação - UDESC. \\
Especialista em Educação a Distância (2012) e MBA em Gestão de Projetos \\
Financeiros (2011). Graduado em Administração (2008). Atualmente exerce \\
a função de Analista de Gestão na área de Inteligência Estratégica da \\
Federação das Indústrias do Estado de SC - FIESC. Atuou como Docente em \\
cursos de pós-graduação (MBA) e graduação, além da Coordenação de Pós- \\
graduação - MBA. Experiência como Consultor na área de Gestão, Liderança, \\
PCS, Avaliação de Desempenho, Pesquisa de Clima e Qualidade no Núcleo de \\
Gestão Empresarial do SENAI/SC em Florianópolis. Avaliador do MPE Brasil \\
2010 e 2011 e do PNQ ciclos 2012 e 2013. \\
Vieira
\end{tabular}

Originais recebidos em: 29/05/2013

Texto aprovado em: 15/10/2013 


\section{APÊNDICE A}

Instrumento de Pesquisa

1. Município

$\square$ Igrejinha

$\square$ Parobé

$\square$ Riozinho

$\square$ Rolante

$\square$ Taquara

$\square$ Três Coroas

2. Cargo do entrevistado

$\square$ Sócio/Proprietário $\square$ Diretor

$\square$ Gerente

$\square$ Supervisor/Técnico

$\square$ Outro

3. Você tem conhecimento dos Serviços Técnicos e Tecnológicos prestados pelo SENAI?
$\square \operatorname{Sim}$
$\square$ Não
$\square$ Não sabe

4. Sua empresa tem necessidade de contratação dos Serviços Técnicos e Tecnológicos prestados pelo SENAI?

$\square \operatorname{Sim} \quad \square$ Não (pule para questão 6) $\quad \square$ Não sabe (pule para questão 6)

5. Especifique quais as necessidades de sua empresa para contratação de Serviços Técnicos e Tecnológicos:

$\square$ Pesquisa Aplicada $\square$ Serviços Laboratoriais

$\square$ Design

$\square$ Serviços de Inspeção

$\square$ Serviços Operacionais

$\square$ Estudos de Mercado

$\square$ Eventos Técnicos

$\square$ Certificação de Processos

$\square$ Certificação de Produtos

$\square$ Assessoria e Consultoria em Gestão Empresarial

$\square$ Assessoria e Consultoria em Processo Produtivo

$\square$ Assessoria e Consultoria em Saúde e Segurança no Trabalho

$\square$ Assessoria e Consultoria em Meio Ambiente

$\square$ Elaboração e Disseminação de Informações (Serviços de Documentação)

6. Qual o nível de conhecimento de sua empresa em relação ao SENAI?
$\square$ Não conhece (pule para a questão 8)
$\square$ Conhece pouco
$\square$ Conhece bem

7. A empresa já utilizou os serviços do SENAI?
$\square$ Nunca utilizou
$\square$ Já utilizou pouco
$\square$ Já utilizou muito

8. Se a empresa nunca utilizou ou utilizou pouco os produtos e serviços do SENAI, indique as principais razões: (esta questão permite múltiplas respostas)

$\square$ Deficiência na divulgação

$\square$ Distância da unidade do SENAI em relação a sede ada empresa

$\square$ Equipamentos desatualizados

$\square$ Horário inadequado de atendimento

$\square$ Inadequação dos serviços do SENAI em relação às necessidades da empresa

$\square$ Inexistência de atendimento específico para o setor

$\square$ Prazo de atendimento além da expectativa da empresa

$\square$ Lentidão no atendimento às solicitações da empresa

$\square$ Período inadequado para a realização das atividades

$\square$ Preços altos 